\title{
Sources and types of information on self-care symptom management strategies for HIV and AIDS
}

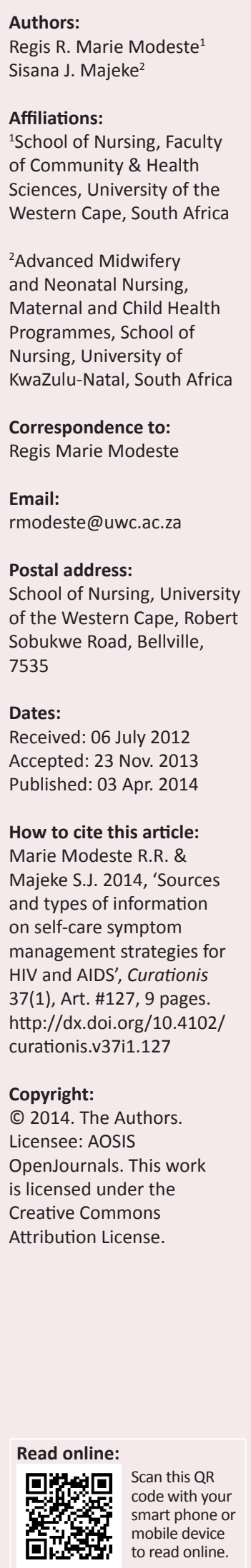

Background: It has been reported that South Africa has the highest number of people living with HIV worldwide, with more women being infected than men. Women living with HIV have been documented as experiencing various symptoms related to HIV and use various strategies to manage these symptoms.

Objective: The objective of this study was to explore the sources and types of information regarding self-care symptom management strategies received by women living with HIV.

Method: The study was conducted at an HIV clinic in an urban area of KwaZulu-Natal. Individual in-depth interviews were completed with 11 women who were living with HIV, exploring the sources of information received on how they manage the HIV- (and/or AIDS-) related symptoms they experienced as well as the types of information received. The collected data were analysed using qualitative content analysis.

Results: The participants identified various sources, which mainly included groups of people who provided them with information on how to manage their HIV-related symptoms, namely healthcare providers, their personal networks and the community. The different sources offered different types of information, including the use of medication, complementary treatments and self-comforting activities.

Conclusion: The study highlights that participants used multiple sources to get information about how to manage the experienced symptoms related to HIV, namely, healthcare providers, family and friends as well as themselves. It is to be noted that each source provided a preferred type of information.

\section{Introduction}

Human Immunodeficiency Virus (HIV) has been known to exist for more than three decades now and there are still new infections being documented, with the recent statistics showing that, in the year 2012, there were about 2.3 (1.9-2.7) million new infections worldwide(UNAIDS [Joint United Nations Programme on HIV / AIDS] 2013:4). Prevention programmes such as the LoveLife HIV prevention programme in South Africa that targets the youth have been established and are running effectively. Prevention programmes are involved in a number of initiatives, including voluntary counselling and testing, treatment for sexually transmitted diseases, condom promotion campaigns, abstinence, prevention of mother-to-child transmission (PMTCT) programmes and many more (Global HIV Prevention Working Group 2004:1). It has been documented, however, that the coverage of prevention programmes is low, as only a fraction of people who are at risk of being infected are able to access proven programmes for prevention (Global HIV Prevention Working Group 2004:1).

People who are living with HIV have been documented as experiencing a number of related symptoms, such as anxiety and depression as well as other physical symptoms, and they use different strategies in order to manage these symptoms (Marie Modeste \& Majeke 2010). Those living with HIV need information on how to manage these symptoms and maintain their health (O’Grady 2008:261; Tsai, Hsiung \& Holzemer 2002:301).

\section{Problem statement}

The symptoms related to HIV (and to acquired immune deficiency syndrome [AIDS]) as well as their management have been well documented in overseas studies (Bunch 2004; Corless et al. 2002; Hudson, Lee \& Portillo 2003; Hughes 2004; Leenerts \& Magilvy 2000; Tsai et al. 2002). In South Africa, HIV-related symptoms have been documented by Shisana et al. (2003:99); and Makoae et al. (2005:27) have reported on symptoms experienced by adults who are living with HIV in Southern Africa. The ability to provide self-care symptom management depends on information that one has regarding how self-care is utilised for the various symptoms that are experienced. 
The information that one has may or may not be accurate or useful. Similarly, the information obtained may be from various sources; one needs to be able to identify who is able to provide the required information for self-care symptom management (Marie Modeste \& Majeke 2010).

Considering that women form the majority of people living with HIV, the stigma associated with the illness puts an additional burden on their lives and they experience many different symptoms related to HIV (and/or AIDS) (Marie Modeste \& Majeke, 2010). There was thus a need to conduct and then share the findings of this study with both colleagues and the community as a whole. It is essential for the community, particularly nurses, midwives and other healthcare professionals, to be knowledgeable about the sources and types of information regarding how to manage the symptoms related to HIV experienced by women living with HIV, as well as what types of information are given to these women.

\section{Background}

With the increase in the availability and access to treatment for HIV, the disease that was considered to be a death sentence in its early years has become more of a chronic illness (Marie Modeste \& Majeke 2010). The virus destroys the infected person's immune system by attaching itself to the cell surface of the CD4 receptor, thereby opening the door for all kinds of opportunistic infections (Marie Modeste \& Majeke 2010; Pratt 1995:64). Currently, antiretroviral medications are being dispensed in all developed countries. In developing countries, however, treatment is not easily accessible to everyone. Of all the people who actually need treatment in those countries classified as low- and middleincome countries, only about $7 \%$ receive antiretroviral medication (Global HIV Prevention Working Group 2004:1; UNAIDS 2008:33). In South Africa, until April 2010, the Department of Health considered the criteria for defining eligibility for antiretroviral therapy as being a CD4+ count of less than 200 cells/ $\mu$ l or being in a 'stage' based on the World Health Organization's (WHO) staging system. Based on these criteria, South Africa's antiretroviral coverage increased to $40.2 \%$ in 2008 from $4.9 \%$ recorded in 2004, with coverage in KwaZulu-Natal being 39.4\% in 2008 (Adam \& Johnson 2009:665). With the current eligibility of a CD4+ count of 350 cells $/ \mu 1$, the antiretroviral uptake will increase.

Nevertheless, similar to many other chronic illnesses, the care for HIV is managed mainly in the home and outpatient setting, resulting in self-care being a very important aspect of the management of HIV and AIDS (Chou \& Holzemer 2004:58; Chou et al. 2004:332; Marie Modeste \& Majeke 2010; Von Korff et al. 1997:1097).

People who live with HIV often present to healthcare facilities when they experience troublesome symptoms (Asch et al. 2004:41; Marie Modeste \& Majeke 2010). Those symptoms have a negative impact on their lives and may be physical, such as skin rash, headaches and diarrhoea, or psychosocial, such as loneliness, anxiety and depression (Holzemer 2002:49; Marie Modeste \& Majeke 2010).

Some of the symptoms that have been documented as being the most frequent and bothersome include diarrhoea, cough and neuropathy, followed by weight loss, depression, fear and anxiety, fatigue, nausea and vomiting (Asch et al. 2004:43; Makoae et al. 2005:27; Shisana et al. 2003:99-100; Tsai et al. 2002:303).

As the management of HIV and AIDS becomes more complex, discussions on self-care symptom management with the healthcare providers become essential. Patients need to be empowered to manage the HIV- and/or AIDSrelated symptoms they are experiencing. Learning how to cope and deal with the symptoms is one of the many experiences people with the infection have to go through (Tsai et al. 2002:301). In the healthcare setting, symptoms are often managed with the use of medication and, in Southern Africa, the majority people who are living with HIV depend on public health services for management (Makoae et al. 2005:30).

The literature indicate that self-care is an essential aspect of symptom management for people who live with HIV, a feature that is important for all chronic illnesses since a diagnosis of HIV is no longer considered to be a death sentence (Chou et al. 2004:332; Marie Modeste \& Majeke 2010).

Self-care comprises all the activities completed by the person infected with HIV in order to improve their health, manage their symptoms, prevent opportunistic diseases and restore their health (Chou et al. 2004:332; Marie Modeste \& Majeke 2010). By adopting a healthy lifestyle, people can keep themselves healthy which is vital because, as the illness progresses, the person infected with HIV is bound to start experiencing an increase in symptoms (Chou et al. 2004:332; Marie Modeste \& Majeke 2010). The self-care symptom management approach discussed in this article focuses on self-care activities aimed at managing the experienced symptoms that have been documented in a previous article by the authors (Marie Modeste \& Majeke 2010).

The various symptoms experienced trigger various self-care symptom management activities. Multiple types of self-care symptom management strategies have been reported to be used by patients in the management of their HIV- and/or AIDS-related symptoms and it has been noted that most patients know at least some self-care symptom management strategies (Chou 2004:110; Chou et al. 2004:336; Holzemer 2002:50; Marie Modeste \& Majeke 2010). The types of strategies that have been documented for self-care symptom management include changing diet, self-comforting, medications, complementary treatment, spiritual care, daily thoughts and/or activities, exercise and seeking help (Chou \& Holzemer 2004:58; Chou et al. 2004:336; Marie Modeste \& Majeke 2010). 
Sources of information about self-care are varied, as has been documented previously; these include the infected person, their friends, healthcare providers and the community (Chou \& Holzemer 2004:58; Chou et al. 2004:335; Hughes 2004:11S).

Self-care strategies are often learned by trial and error (Bunch 2004:172). Other authors have documented sources of information in the literature, namely, peers and professionals (Chou 2004:113); healthcare providers, family, news media, friends and internet (Holzemer 2002:52); and self, healthcare providers, personal networks and communities (Chou et al. 2004:338). However, the stigma attached to HIV makes it difficult for people who are living with HIV to access information on how to manage related symptoms, with confidentiality being an identified issue that inhibits accessing resources where information can be obtained (O'Grady 2008:267).

\section{Research objectives}

This study, conducted in an urban area in the eThekwini district, had the following objectives:

- To explore the perceived sources of information regarding self-care symptom management strategies used by women living with HIV and AIDS.

- To explore the perceived types of information regarding self-care symptom management strategies used by women living with HIV and AIDS.

\section{Purpose of the study}

The purpose of the study was to explore and describe the perceived sources of information as well as the types of information available with regard to self-care symptom management strategies received by women living with HIV in an urban area in the eThekwini district in KwaZulu-Natal.

\section{Significance of the study}

The findings of this study may enlighten healthcare workers and other stakeholders with regard to the sources and types of information on self-care symptom management as used by women in this study who are living with HIV. This may allow identification of sources that need to be strengthened. This knowledge could also be integrated into health education programmes and used to implement effective healthcare that may improve healthcare services offered to people living with HIV.

\section{Research method and design Context of the study}

This study was conducted at an HIV and AIDS care centre, attached to a hospital situated in an urban area of KwaZuluNatal province in South Africa. The centre comprises three linked programmes, namely, a clinic, a training programme and a development programme.

The clinic provides medical and related care and is based at two sites; the first site offers voluntary counselling and testing (VCT) services, testing for CD4 counts, psychosocial assessment and psychosocial-spiritual support. The other site offers comprehensive medical care, including antiretroviral medication, to adults and children. The services offered are blood testing; care and support; and training and medical care for HIV-related problems. The programme provides treatment for PMTCT at the antenatal clinic and antiretrovirals to children and adults who are living with HIV.

\section{Design}

This article presents work performed by the authors in a bigger study that was conducted using a qualitative approach, in exploring and describing the sources of information on self-care symptom management strategies as well as the type of information received by women living with HIV in eThekwini district in KwaZulu-Natal. The population for the study was women living with HIV, who experienced HIVand/or AIDS-related symptoms and resided in an urban area in eThekwini district. All the participants were aged 18 years old and above and all attended the HIV clinic in eThekwini district where the study was conducted.

\section{Sample size and sampling method}

As noted by Polit \& Hungler (1999:297), the sample size in a qualitative research study is determined on the basis of needed information until saturation is reached. In this study, a purposive sampling method was used to select the participants and the researcher reached saturation after interviewing 11 participants. The inclusion criteria were being a woman living with HIV, having experienced at least four symptoms related to HIV, being able to speak English and aged 18 years and above, as it is only at this age that consent can be obtained without requiring permission from parents or guardians. To ensure that participants had experienced symptoms related to HIV, they were screened using the 'Revised Sign and Symptom Check-List for Persons with HIV Disease' (SSC-HIVrev) instrument (Holzemer et al. 2001:68). A total of 13 women living with HIV and attending the clinic where the study was conducted were contacted, 11 of whom participated in the study.

\section{Data collection}

The collection of data was carried out in a private room at the institution and was conducted by means of individual in-depth interviews which lasted about 30-60 minutes each. The researcher tape recorded all the interviews and transcribed the interviews verbatim. The researcher obtained signed informed consent from participants and permission was requested in order to tape record the interviews. The researcher needed to have the interview tape recorded so as to provide an opportunity for transcription of the interviews, which would be needed for the data analysis. In addition, this eliminated the possibility of forgetting what was discussed in the interviews, as the transcribed interviews could be read over again to gain clarification on the discussion. The researcher asked open-ended questions, followed by further questions for probing, and these were used to guide the 
interviews. The interview guide consisted of two sections. The first part included questions about the participant's background and demographics in order to offer a description of the sample. The second part consisted of guiding questions to be used by the researcher in the individual in-depth interviews, in order to ensure that data collected would answer the research questions. After exploring the experienced HIV-related symptoms, the participants were asked to specify the source of information for the specific self-care symptom management strategy applied to deal with the symptoms that they experienced.

\section{Data analysis}

Data collection and data analysis were carried out at the same time. Data analysis in qualitative research has a series of steps, beginning at the start of the data collection phase. The steps include coding for categories and themes, verifying the selected themes and discussing the themes with other researchers so as to refine the categories (Brink 1996:192).

The analysis followed the eight coding steps as suggested by Carley (1992, quoted in Busch et al. 2005:3).

The level of analysis chosen was the set of words. This choice was useful as it allowed the researcher to put together words that are different but mean the same thing. The sources of information were coded based on the four categories documented by Chou et al. (2004:336), as is described below. The categories were coded for their presence in each unit of analysis, not on their frequencies. The concepts were distinguished by identifying the level of generalisation of the categories and themes and the coding was done, not by the form of the concepts but with emphasis on the meaning of the concepts. A deductive application was the chosen method in the analysis. Information that was not related to the issues covered in the research questions and objectives was re-examined in order to identify any other information that could be useful for the study and for the knowledge and understanding of self-care symptom management of people who are with HIV. Transcripts were coded manually and the results were analysed.

The sources of information were coded based on the following four categories documented by Chou et al. (2004: 336):

- Self: The source of information that was self-taught, or practised by trial and error by the participants themselves.

- Healthcare provider: Where information was obtained from any person working in a health institution, such as a doctor, clinic and hospital staff as well as traditional healers.

- Personal network: Information learnt from someone close to the family or within the social network, such as a family member or a friend.

- Community: Sources from the external environment such as media and reading.

\section{Description of the participants}

In this study, all participants were women who are living with HIV; they were all aged 18 years and above; and they had experienced symptoms related to HIV and/or AIDS as established during the selection process using the SSC-HIVrev instrument (Holzemer et al. 2001: 68). The participants' ages varied from 25 to 57 years. The participants reported knowing their HIV status for a period ranging from less than a year to a maximum of nine years. Of the 11 participants, five reported being unemployed and only two participants stated that two people were considered to be the breadwinners in their household, whilst four participants reported being the only breadwinner in their household. Looking at how many people live in the same household, the number ranged from one to 14. Seven of the participants reported that there were at least two other people living with them, whilst only one participant said that she lived alone. Two participants had never been to high school and only three had completed high school. The majority of the participants were Christians, with only one participant reporting to belong to the Shembe (Nazareth) religion. Religion was viewed as being 'very important' in the lives of most of the participants, with only one participant reporting that it was 'important', whilst another one felt it was 'not at all important' in her daily life.

\section{Results}

Three sectors of healthcare have been documented in the literature, namely, the popular sector, folk sector and professional sector (Helman 2007:82). Lay non-professionals, church activities, friends and family are identified as being part of the popular sector; the folk sector includes the traditional healers; whilst the professional sector includes modern medical professionals (Helman 2007:82). The participants in this study reported using these three sectors and received help from different sources, including healthcare institutions, churches and traditional healers. The participants reported getting help from more than one source; this was mainly from healthcare institutions such as a clinic, hospital or private doctor, but also from traditional healers. There was only one participant who reported getting help from her church, whilst another participant reported not getting any help and merely enduring her symptoms, as is reflected in Table 1.

The majority of the participants relied on healthcare providers for help in the management of symptoms related to HIV. Clinics were most often mentioned as the source of help. This may be explained by the fact that South Africa adopted the primary healthcare approach as part of its healthcare system and people are encouraged to access health services from their nearest clinics, with referrals only being made to hospitals when necessary (Coovadia et al. 2009:828) . Very few relied on community aid such as a church as a source of help, or on other members in their community.

TABLE 1: The reported sources of help in general.

\begin{tabular}{lll}
\hline Help & Sources & Number of participants $(N=11)$ \\
\hline Healthcare provider & Clinic & 6 \\
& Hospital & 4 \\
& Private doctor & 3 \\
& Traditional healer & 3 \\
Community & Church & 1 \\
None & & 1 \\
\hline
\end{tabular}




\section{Sources of information on symptom management in general}

All participants reported that they had received information about the management of symptoms related to HIV and AIDS. Most of the participants got this information from healthcare providers such as hospital staff, clinic staff and counsellors. In this study, the media was also reported by some of the participants as being one of the sources of information on how to manage the symptoms, as were friends. Only one participant reported that her source of information on symptom management was traditional healers. Hospital staff were mentioned most often as being a source of information, which suggests that as their symptoms worsened, the participants had been referred to hospitals from their nearest clinics. Again, community and personal networks were reported less often as sources of information on how to manage the experienced symptom(s).

\section{Sources of information on self-care symptom management}

The sources of information described regarding self-care symptom management strategies included self, where the participants had taught themselves which strategy to adopt for self-care symptom management in order to ease the experienced symptoms. Other sources of information on strategies used for self-care symptom management were healthcare providers, personal networks (including family members and friends) and the community (including the media), which is similar to what has been document previously by Nicholas et al. (2002:768).

\section{Self}

Participants themselves developed self-care symptom management strategies. The experience of pain drove some participants to try out different strategies to find anything that would help ease the symptoms. The strategies for selfcare symptom management that the participants had taught themselves were performed through trial and error. These strategies were mainly self-comforting activities, that is to say, activities that the participants felt would solve the problem and the discomfort that was being felt at a certain moment by targeting what was believed to have triggered the symptom. An example is that of Participant 2 who, in order to manage her backache, stated:

'... I always put something between me and the wall, and drink warm things, to stop the cold... I just tried it'. (P2, Female, 57)

In addition, another participant, when managing night sweats, stated:

'I wake up in the night and then I take off my clothes and sleep without having anything on... I just did'. (P9, Female, 34)

This practice appears to be consistent with what was noted with people living with HIV in Norway (Bunch 2004:173).

\section{Healthcare providers}

Healthcare providers were another source of information on self-care symptom management strategies; these included hospital or clinic staff and doctors, especially private doctors. The type of information obtained from healthcare providers was mostly related to the medication that was taken to ease the experienced symptoms. This was noted by participants such as Participant 4, who stated:

'I used to go to the clinic; they just give me something to apply on the skin'. (P4, Female, 30)

and Participant 7, who stated:

'.. then I went to a private doctor, she gave me another medicine, white...'. (P7, Female, 28)

Participant 7 also said:

'... if I am sick, doctor gives me medicine'. (P7, Female, 28)

These reports again highlight the use of and trust in the healthcare providers by the participants. The reports also show that healthcare providers tend to focus mainly on medication as a way of managing HIV-related symptoms, in some cases with little or no emphasis on other forms of selfcare symptom management strategies.

There were, nevertheless, instances where strategies other than medication were described by participants as being included in the information given by healthcare provider. Some participants described being informed about changing their diet and complementary treatment, such as harm reduction activity by stopping the use of traditional medication. This was noted in the individual in-depth interviews, as seen, for example, when Participant 3 stated that she had learnt from the clinic about changing her diet strategy. In addition, Participant 11 stated:

'I drink a lot of water, about 5 to 6 glasses of water ... I learnt about it from the hospital'. (P11, Female, 41)

Participant 7 also noted that the healthcare providers had given her information rather than medication:

'... because my doctor said if I drink all that the treatment is not gonna be alright because if you drink medicine for African and drink medicine for doctor is not right because this one will affect this one. So I stopped it'. (P7, Female, 28)

Traditional healers were not described as being a source of information on self-care symptom management strategies. This might be explained by the fact that the participants were contacted at an institution where the use of traditional medication would not be encouraged because combining western and traditional medication could result in more severe problems. It could also be, as noted by Sukati et al. (2005:191), that traditional practices do not allow the patients themselves to solicit the healer's aid; rather the head of the family or a close family member should act on behalf of the patient. Considering that the participants were women, their male partner or relatives may have been the ones acting on their behalf.

\section{Personal network}

One's personal network was also reported by participants in this study as being a source of information regarding self- 
care symptom management strategies. This network circle includes friends, a spouse, parents, children and employers. The information gathered from the personal network was mainly about complementary treatment such as the use of traditional medication and other natural medication, followed by help seeking and medication. This was described by some of the participants such as Participant 11, who said:

'... my husband advised me [to take the cough mixture]'. (P11, Female, 41)

and Participant 2, who reported:

'... someone told me I should try it [African potato], a friend'. (P2, Female, 57)

\section{Participant 6 stated:}

'... my mother teach me that [soaking feet in hot water to manage pain in her toes]'. (P6, Female, 25)

This is similar to what was noted by Eller et al. (2005:125), namely that family and friends recommended mainly complementary therapy as self-care symptom management strategies.

\section{Community}

The community was also described as being a source of information on self-care symptom management strategies. This included media reports on the use of traditional medication. Participant 4 described how she learnt how to manage HIV-related symptoms:

'I heard it [African herbs] from the radio, and I used to get paper on the street about it'. (P4, Female, 30)

There were few descriptions of the media as a source of information on self-care symptom management strategies, despite the availability of television programmes such as 'Siyayinqoba Beat It!'. This is a television programme which provides treatment literacy and related information for people living with HIV, as well as some brochures, such as the one released by Soul City that addresses HIV- and AIDSrelated issues, including the symptoms of HIV and AIDS.

When the newly-learnt strategies were used, their outcome varied. Some strategies provided relief, others provided limited relief, whilst some provided no relief at all. In this study, the self-taught activities were mainly self-comforting activities and they were the ones most often reported as being effective.

\section{Types of information on self-care symptom management strategies}

Eight categories of self-care symptom management strategies that are used by people experiencing HIV- and/ or AIDS-related symptoms have been documented in the literature, highlighting that people who are living with HIV not only look for help with medication, but also use other non-pharmaceutical strategies to manage the experienced symptoms (Chou et al 2004:335). The identified self-care symptom management strategies that have been identified in this study included the following six strategies:

- Changing diet: All reports on any change in diet, careful attention paid to what is eaten, or cooking methods were coded under this category.

- Complementary treatment: This strategy comprised reports of harm-reducing activities or taking of any treatment assumed to have a healing effect on the symptoms, such as traditional medicine, herbs and other natural medicines.

- Daily thoughts: This category comprised activities or thoughts that were practised in order to ease the experience of symptom(s). Endurance was also coded in this category and taken as a daily thought as it requires the participant to adjust to the new sensation of the symptom.

- Help seeking: This strategy relates to reports where participants were encouraged to go for any support or help; going to any healthcare provider, such as a doctor; going to a healthcare institution, such as a hospital and a clinic; and talking to other people, including friends or a support group.

- Medication: This included reports on taking medication that was prescribed or bought over the counter as well as routine medication taking.

- Self-comforting activities: These were activities that were performed to make the client feel better by providing immediate comfort, but had no healing effect on the symptom(s). These included going to sleep, massage, taking off clothes, taking warm drinks and washing.

The types of information noted in this study are similar to the types of strategies identified for self-care symptom management as documented by Chou et al (2004:336). However, in this study, it is to be noted that there was very little information regarding exercising and spiritual care. Spiritual care as a strategy includes all spiritual activities such as praying, going to church and reading the Bible, whilst exercise includes any activity performed to exercise the body such as jogging, aerobics, walking and on the like. This is different from what was documented in other studies where a self-care strategy of exercise was used and found effective for different symptoms related to HIV (Bunch 2004:173; Kemppainen et al. 2006:602). Furthermore, it is to be noted that each source of information had a preferred type of information that they provide to the women living with HIV.

\section{Ethical considerations}

For the bigger study, ethical clearance was obtained from the University of KwaZulu-Natal's ethics committee, as well as from the hospital's ethics committee, for permission to conduct the research at the clinic used by the participants. The participants were accessed through the healthcare providers who referred them to the researcher. The interviews were conducted by the researcher in a private room not utilised by healthcare providers at the centre. The researcher informed the clients about the purpose and significance of the study and then invited them to participate in the study. An information sheet with information related to the study, its purpose and 
significance was also given to the participants to allow them to make an informed decision about their participation in the study.

Participants were informed about the possible advantages and inconveniences of participating in this study, such as the time to be spent during the individual in-depth interviews, and were informed that they could withdraw at any time they so wished. Once the participant agreed to be part of the study, a consent form was signed by the participant and kept by the researcher in order to ensure that participants were known only to the researcher. As noted by Burns \& Grove (2001:206), an informed consent comprises four important elements, namely comprehension, disclosure of essential information, competence and voluntarism, was all of which were complied with in this study. Information about the participants was kept confidential as only people involved in the study had access to it and participants' anonymity was ensured by allocation of a number for each participant instead of using their names. The risks associated with participating in the study, such as emotional stress, were kept to a minimum. Although no participant stated experiencing any risk resulting from participating in the study, referrals to a psychologist and/or social worker at the centre were available in order to minimise any possible discomfort. The researcher ensured that the participants were not harmed in any way, by protecting their identity. No information was retained if it was not related to the present study. As a sign of gratitude, participants were given an information handout on nutrition for people living with HIV and AIDS, compiled and donated by the South African Sugar Association as planned for the bigger study (Marie Modeste \& Majeke 2010).

\section{Trustworthiness}

To ensure the quality of data and findings in this study, steps were taken to ensure the credibility, dependability, confirmability and transferability of the data (Polit \& Hungler 1999:427). Credibility was achieved by the prolonged engagement. The data collection was carried out over three months (end of January 2006 until early April 2006), giving the researcher time to gain an understanding of the collected data. In addition, participant checks and debriefing were carried out by giving feedback on the data to the participants during their interviews. Keeping records of all phases of the research process and getting the research process audited ensured dependability. To ensure transferability, in-depth discussion and rich description of the details of the methods used in data collection and data analysis, as well as the setting, were provided. Through bracketing and reflexivity, the researcher tried to ensure that personal values and beliefs did not influence the research findings (Bryman 2004:276).

\section{Discussion}

The major sources of information on self-care symptom management strategies that were described by participants in this study were healthcare providers, self and the personal network. The popularity of healthcare providers as sources of help has been noted in other research studies performed in Southern Africa (Sukati et al. 2005:190). However, healthcare providers were the least-reported source of help after self, personal network and community in studies conducted in western countries (Chou et al. 2004:335). Adolescents in Swaziland have reported healthcare providers as their third source of information on HIV and AIDS after the media, siblings and friends, despite having reported that healthcare providers were their preferred sources of information on HIV and AIDS (Buseh et al. 2002:530).

Participants described each category or source of information as offering different types of information on the strategies of symptom management to be used in relation to HIV and AIDS.

\section{Healthcare providers}

The category of healthcare providers is made of mainly healthcare professionals, including nurses, doctors, and clinic and hospital staff. In this study, healthcare providers were described as emphasising a pharmacological approach in the management of HIV- and/or AIDS-related symptoms and mainly gave types of information on the use of medication for the symptoms experienced. Healthcare providers were also reported to have given information on diet, such as one who advised increased fluid intake. Also, harm-reduction activities were also reported, such as in the case of one participant who was informed by a healthcare provider that she should stop taking traditional medicine in case it interfered with the other medication she was receiving. The trust and reliance in healthcare providers with regard to provision of information has also been noted by De Wet, Du Plessis and Klopper (2013).

\section{Self}

Contrary to the healthcare providers' types of information, the self-taught self-care symptom management strategies were mainly self-comforting activities to ease the experienced symptoms, such as going to sleep, massage and taking off their clothes. These types of self-care symptom management strategies were very often learnt by trial and error.

These findings are similar to those noted in other studies, in that healthcare providers give patients information regarding medication, whereas people actually living with HIV would teach themselves mainly self-comforting strategies, amongst others (Chou et al. 2004:335; Eller et al. 2005:124; Sukati et al. 2005:188).

\section{Personal networks}

In this study, complementary treatments were the type of information often learned from participants' personal network, most commonly their family members. These findings are similar to what was reported by Eller et al. (2005:125). In another South African study on patients living with HIV and their families' understanding of information related to HIV and AIDS, family members were reported 
by more than half the participants as being their source of information (De Wet et al. 2013).

\section{Community}

The community as a source of help was seldom cited in this study, contrary to what has been noted in other studies (Chou et al. 2004:335; De Wet et al. 2013; Sukati et al. 2005:190). This is a matter of concern because of the large number of people living with HIV in South African communities (Marie Modeste \& Majeke 2010). They should be able to gain sufficient information about their symptom management from the communities in which they are living. In the study done by Sukati et al. (2005:190), respondents received information from the community mainly about help seeking and spiritual care strategies, whilst Chou et al. (2004:335) reported that the community was the main source of information regarding spiritual care strategies to manage symptoms related to HIV and AIDS.

\section{Limitations}

The scope of this study was limited and the study did not look at details of sources of information about the self-care symptom management strategies for specific symptoms that are experienced by women living with HIV. This was mainly because of the diversity of HIV-and/or AIDS-related symptoms being experienced by the participants.

All the participants in the study were African women whose first language was isiZulu and the findings presented in this study can therefore not be generalised to other race groups living with HIV in the area where the study was conducted. Nevertheless, as most residents in this district are African and most of the clients in the health institutions are African, the findings may apply more generally.

As the researcher in this study was fluent in English and not isiZulu, all the individual in-depth interviews were done only in English, with participants who were also fluent in English. As a result, women who were living with HIV who could only communicate in one or more African languages and those who were not able to express themselves in English were not included in the study.

\section{Recommendations}

The recommendations from this study are presented for two groups of stakeholders, namely healthcare providers and religious ministers.

\section{Recommendations for healthcare providers}

Healthcare providers need to be able to manage people living with HIV in a holistic way, guiding them with regard to selfcare symptom management strategies other than medication (Marie Modeste \& Majeke 2010). Once this is achieved, it would reduce the overload on healthcare services as patients would be empowered and would be able to manage some of their symptoms at home. They would only need to report to healthcare providers with symptoms that are beyond their ability. The participants in this study did not know much about some of the medications that they had received from healthcare institutions, which shows that limited information is being given to patients in those institutions. Furthermore, more research is needed to be done by healthcare providers, especially nurses, in order to establish the various sources of information regarding the self-care of patients living with HIV, the types of information being received and, most importantly, to establish the efficacy of the learnt types of information.

\section{Recommendations for religious ministers}

In this study, participants infrequently described religious institutions as being a source of information, despite the fact that religion was described as being very important in their daily lives. Based on findings from other studies that women living with HIV benefited from spiritual care (Chou 2004:113), religious ministers should be encouraged to support people living with HIV in their congregations and be provided with training about the management of symptoms related to HIV and AIDS. This would increase the support base for people who live with HIV in the communities in which they are based, whilst at the same time maintaining consistency in the information being given to those experiencing HIV-related symptoms.

\section{Conclusion}

The findings in this study are similar to what has been documented by other researchers, notably that people who live with HIV use multiple sources to gather information about how to manage the symptoms related to their infection. These sources are not only the healthcare providers, but also include self as well as family and friends (Chou et al. 2004:338).

The participants in this study benefited from different sources of information, including healthcare providers, the participants themselves, their personal network and, to a lesser extent, the community. Each source of information appeared to have a preferred type of strategy for self-care symptom management. Healthcare providers recommended mainly medications, the personal networks recommended mainly complementary treatment, whilst the participants themselves tried self-comforting strategies.

\section{Acknowledgements}

The authors would like to thank Prof K. Nokes for the guidance and hours of consultation provided in the early stages of this project.

They would also like to thank the South Africa Sugar Association for donating the leaflets with information on nutrition and the HIV-positive person that were given to each participant. 


\section{Competing interests}

The authors declare that they have no financial or personal relationship(s) which may have inappropriately influenced them in writing this article.

\section{Authors' contributions}

R.R.M.M. (University of the Western Cape) conducted the research and wrote the manuscript. S.J.M. (University of KwaZulu-Natal) provided supervision and guidance throughout the duration of the research project and the completion of the manuscript.

\section{References}

Adam, M.A. \& Johnson, L.F., 2009, 'Estimations of adult antiretroviral treatment coverage in South Africa', South African Medical Journal, 99(9), 661-667.

Asch, S.M., Fremont, A.M., Turner, B.J., Gifford, A, McCutchan, J.A., Mathews, W.M. et al., 2004, 'Symptom-based framework for assessing quality of HIV care', International Journal for Quality in Health Care, 16(1), 41-50. http://dx.dol. org/10.1093/intqhc/mzh004

Brink, H., 1996, Fundamentals of research methodology for health care professionals, Juta \& Company, Cape Town.

Bryman, A., 2004, Social research methods, 2nd edn., Oxford University Press, New York.

Bunch, E.H., 2004, 'Symptom management for HIV-positive persons in Norway', International Nursing Review, 51(3), 167-175. http://dx.doi.org/10.1111/j.14667657.2004.00232.x

Burns, N. \& Grove, S.K., 2001, The practice of nursing research: conduct, critique \& utilization, 4th edn., WB Saunders, Philadelphia.

Buseh, A.G., Glass, L.K., McElmurry, B.J., Mkhabela, M. \& Sukati, N.A., 2002, ‘Primary and preferred sources for HIV/AIDS and sexual risk behavior information amon adolescents in Swaziland, Southern Africa', International Journal of Nursing Studies, 39(5), 525-538. http://dx.doi.org/10.1016/S0020-7489(01)00058-X

Carley, K., 1992, MECA, Pittsburgh, PA, Carnegie Mellon University, quoted in C. Busch, et al., 2005, 'Content Analysis', viewed 29 Dec 2013, from http://writing.colostate. edu/guides/pdfs/guide61.pdf

Chou, F.Y., 2004, 'Testing a predictive model of the use of HIV/AIDS symptom self care strategies', AIDS Patient Care and STDs, 18(2), 109-117. http://dx.doi. org/10.1089/108729104322802533

Chou, F.Y. \& Holzemer, W.L., 2004, 'Linking HIV/AIDS clients' self-care with outcomes', Journal of the Association of Nurses in AIDS Care, 15(4), 58-67. http://dx.doi. org/10.1177/1055329003255592

Chou, F., Holzemer, W.L., Portillo, C.J. \& Slaughter, R., 2004, 'Self-care strategies and sources of information for HIV/AIDS symptom management', Nursing Research, 53(5), 332-339. http://dx.doi.org/10.1097/00006199-200409000-00008

Corless, I.B., Bunch, E.H., Kemppainen, J.K., Holzemer, W.L., Nokes, K.M., Eller, L.S. et al., 2002, 'Self-care for fatigue in patients with HIV', Oncology Nursing Forum, 29(5), E60-E69. http://dx.doi.org/10.1188/02.ONF.E60-E69

Coovadia, H., Jewkes, R., Barron, P., Sanders, D. \& Mclntyre, D., 2009, 'The health and health system of South Africa: historical roots of current public health challenges', The Lancet, 374(9692), 817-834. http://dx.doi.org/10.1016/S01406736(09)60951-X

De Wet, G.E., Du Plessis, E. \& Klopper, H.C., 2013, 'HIV-positive patients' and their families' comprehension of HIV- and AIDS-related information', Health $S A$ Gesondheid, 18(1), Art. \#597, 11 pages. http://dx.doi. org/10.4102/hsag. v18i1.597
Eller, L.S., Corless, I., Bunch, E.H., Kemppainen, J., Holzemer, W., Nokes, K., et al., 2005, 'Self-care strategies for depressive symptoms in people with HIV disease', Journal of Advanced Nursing 51(2).119-130. http://dx.doi.org/10.1111/j.1365Journal of Advanced

Global HIV Prevention Working Group, June 2004, 'HIV prevention in the era of expanded treatment access', viewed 29 December 2013, from http://www.unicef. org/aids/files/HIV-Prevention-in-the-Era-of-Expanded-Treatment-Access.pdf

Helman, C.G., 2007, Culture, health and illness, 5th edn., Hodder Arnold, London.

Holzemer, W.L., 2002, 'HIV and AIDS: the symptom experience. What cell counts and viral loads won't tell you', American Journal of Nursing, 102(4), 48-52. http:// dx.doi.org/10.1097/00000446-200204000-00023

Holzemer, W.L., Hudson, A., Kirksey, K.M., Hamilton, M.J. \& Bakken, S., 2001, 'The revised sign and symptom check-list for HIV (SSC-HIVrev)', Journal of the Association of Nurses in AIDS Care, 12(5), 60-70. http://dx.doi.org/10.1016/ S1055-3290(06)60263-X

Hudson, A.L., Lee, K.A. \& Portillo, C.J., 2003, 'Symptom experience and functional status among HIV-infected women', AIDS Care, 15(4), 483-492. http://dx.doi. status among HIV-infected women',
org/10.1080/0954012031000134728

Hughes, A., 2004, 'Symptom management in HIV-infected patients', Journal of the Association of Nurses in AIDS Care, 15(5 Suppl), 7S-13S. http://dx.doi the Association of Nurses in AlDs
org/10.1177/1055329004269477

Kemppainen, J.K., Eller, L.S., Bunch, E., Hamilton, M.J., Dole, P., Holzemer, W., et al., 2006, 'Strategies for self-management of HIV-related anxiety', AIDS Care, 18(6), 597-607. http://dx.doi.org/10.1080/09540120500275726

Leenerts, M.H. \& Magilvy, J.K., 2000, 'Investing in self-care: A midrange theory of selfcare grounded in the lived experience of low-income HIV-positive white women' Advances in Nursing Science, 22(3), 58-75. http://dx.doi.org/10.1097/00012272200003000-00006

Makoae, L.N., Seboni, N.M., Molosiwa, K., Moleko, M., Human, S., Sukati, N.A., et al., 2005, 'The symptom experience of people living with HIV/AIDS in Southern Africa', Journal of the Association of Nurses in AIDS Care, 16(3), 22-32. http:// dx.doi.org/10.1016/j.jana.2005.03.005

Marie Modeste, R.R. \& Majeke, S.J., 2010, 'Self-care symptom management strategies amongst women living with HIV and AIDS in an urban area in KwaZulu-Natal', Health SA Gesondheid, 15(1), Art. \#509, 8 pages. http://dx.doi.org/10.4102/hsag. v15i1.509

Nicholas, P.K., Kemppainen, J.K., Holzemer, W.L., Nokes, K.M., Eller, L.S., Corless, I.B., et al., 2002, 'Self-care management for neuropathy in HIV disease', AIDS Care, 14(6), 763-771. http://dx.doi.org/10.1080/0954012021000031831

O'Grady, L., 2008, 'Meeting health information needs of people with HIV/AIDS: sources and means of collaboration', Health Information and Libraries Journal, 25(4), 261-269. http://dx.doi.org/10.1111/j.1471-1842.2007.00764.x

Polit, D.F. \& Hungler, B.P., 1999, Nursing research: principle and methods, 6th edn., Lippincott, Philadelphia.

Pratt, R., 1995, HIV and AIDS: a strategy for nursing care, 4th edn., Edward Arnold, London.

Shisana, O., Hall, E., Maluleke, R.K., Stoker, D.J., Schwabe, C., Colvin, C., et al., 2003 The impact of HIV/AIDS on the health sector: national survey of health personnel, ambulatory and hospitalised patients and health facilities, 2002, HSRC Press, Pretoria.

Sukati, N.A., Mndebele, S.C., Makoa, E.T., Ramukumba, T.S., Makoae, L.N., Seboni, N.M., et al., 2005, 'HIV/AIDS symptom management in Southern Africa', Journal of Pain and Symptom Management, 29(2), 185-192. http://dx.doi.org/10.1016/j. jpainsymman.2004.05.007

Tsai, Y.F., Hsiung, P.C. \& Holzemer, W.L., 2002, 'Symptom management in Taiwanese patients with HIV/AIDS', Journal of Pain and Symptom Management, 23(4), $301-$ 309. http://dx.doi.org/10.1016/S0885-3924(01)00413-4

UNAIDS, 2008, 2008 Report on the global AIDS epidemic, Geneva, UNAIDS.

UNAIDS, 2013, Global report: UNAIDS report on the global AIDS epidemic 2013, Geneva, UNAIDS.

Von Korff, M., Gruman, J., Schaefer, J., Curry, S.J. \& Wagner, E.H., 1997, 'Collaborative management of chronic illness', Annals of Internal Medicine, 127(12), 1097-1102. http://dx.doi.org/10.7326/0003-4819-127-12-199712150-00008 